\title{
Preparation and Characterization of Bio-Adsorbent from Coconut Husk for Remazol Red Dye Removal
}

\author{
Rohani Mustapha ${ }^{1}{ }^{\mathbb{D}}$, Mohammad Hakim Che Harun ${ }^{1}{ }^{(\mathbb{D})}$, Ayuni Manas ${ }^{1}$, Asmadi Ali ${ }^{1}$, \\ Sofiah Hamzah 1,* (D) \\ 1 Environmental Sustainable Material Research Interest Group, Faculty of Ocean Engineering, Technology and Informatics, \\ Universiti Malaysia Terengganu, 21030 Kuala Nerus, Terengganu Malaysia \\ * Correspondence: sofiah@umt.edu.my;
}

Scopus Author ID 54954085300

Received: 5.08.2020; Revised: 18.09.2020; Accepted: 20.09.2020; Published: 24.09.2020

\begin{abstract}
This study aimed to evaluate the effectiveness of bio-adsorbent from coconut husk for the removal of remazol red dye. The characteristics of coconut husk bio adsorbent are studied using Fourier transform infrared (FT-IR) and scanning electron microscope (SEM). The effects of different types of adsorbent and the effects of initial dye concentration on the removal of remazol red dyes were evaluated. The results showed that the percentage removal of remazol red dye by the treated bio adsorbent is higher compared to the untreated bio adsorbent, especially by activated coconut husk with 5 hours burning time in the furnace. The SEM results also show that the treated bio adsorbent morphology is more porous and rougher to improve the adsorption process. Meanwhile, FTIR analysis shows the reduction of peaks because of the removal of much lignin and hemicelluloses. The best adsorbent recorded is activated coconut husk at 5 hours burning time when it achieved $75 \%$ removal.
\end{abstract}

Keywords: bio adsorbent; dye removal; wastewater; coconut husk.

(C) 2020 by the authors. This article is an open-access article distributed under the terms and conditions of the Creative Commons Attribution (CC BY) license (https://creativecommons.org/licenses/by/4.0/).

\section{Introduction}

The presence of dye in water is due to the plastics, pulp, dyestuffs, paper, and textile effluents of the chemical industries. This problem has increased concern for environmentalists. The removal of dye for wastewater treatment even at very low concentrations is very challenging because it easily visible and undesirable [1]. The presence of dyes in water will lead to extreme water contamination that includes toxic metals that would have a detrimental impact on health-related issues such as cancer, allergy, skin irritation, and dermatitis [2-5]. The remediation of wastewater with dyes remains a major challenge because of their solubility in water, complex structure, and synthetic origin of the dyes. Typical techniques for water and wastewater remediation are membrane filtration, reverse osmosis, chemical precipitation, reduction, oxidation, and adsorption. Nonetheless, these approaches have some drawbacks, such as high capital or operating costs, and result in excess sludge formation [4-6]. Thus, some of these methods are not suitable for small-scale industries. Conversely, adsorption became recognized as an economical and efficient tool for wastewater treatment [7-9]. Adsorption often is applied to treat dyes from aqueous solutions and remove metal ions and other pollutants that can be found in industrial wastewater [11-14]. Compare to other methods, physical adsorption has been found to be an excellent process of advanced wastewater treatment that reduces the hazardous pollutants contained in the effluent as they provide flexibility and simplicity of 
design, effectiveness, insensitivity to toxic pollutants, and low cost [13-15]. The most widely used adsorbent in wastewater treatment systems is activated carbon. However, activated carbon is relatively expensive, and the price depends on the quality of the activated carbon $[1,3,9]$. Therefore, the latest technology, the researcher used biomass-based adsorbents or bioadsorbent for the removal of metal ions or organic compounds. There are a lot of advantages when using bio-adsorbent in removing the dye in wastewater treatment include low cost, high efficiency, and reduction in the formation of chemical and biological sludge [7, 11-12]. Growing demand for the adsorption process in the wastewater treatment had encouraged research in the production of adsorbent or conventional methods from wastes, including industrial wastes and agricultural waste by-products, and even food waste. This is because the production of adsorbent from solid wastes is one of the most environmentally sustainable solutions by converting negative waste into a profitable commodity. Thus, in this study, the performance of bio-adsorbent from coconut husk in removing dyes was studied. The properties of coconut husk were characterized and the adsorption study was examined by the adsorption isotherm of dyes using Langmuir and Freundlich isotherm.

\section{Materials and Methods}

\subsection{Reagents and materials.}

Coconut husk was collected from a coconut stall at Pasar Chabang Tiga, Kuala Terengganu. The husk was extracted from the outer layer of the coconut shell, which usually regarded as domestic waste. Other materials, such as ammonium chloride $\left(\mathrm{NH}_{4} \mathrm{Cl}\right)$, remazol red dye, and zinc chloride $\left(\mathrm{ZnCl}_{2}\right)$ were obtained from Sigma-Aldrich Malaysia.

\subsection{Preparation of raw coconut husk.}

Initially, coconuts were separated from the shell. The shell was then immersed in tap water for $1 \mathrm{~h}$ and followed by well-scrubbed using a sponge and sun-dried for $3 \mathrm{~h}$. Afterward, the dry shell was split into smaller parts using a hammer and was further dried in an oven for $5 \mathrm{~h}$ at $105^{\circ} \mathrm{C}$. The shell was then ground and sieved to $850 \mu \mathrm{m}$ (micrometer mesh). Finally, the shell particles were put in an oven for $30 \mathrm{~min}$ at $30^{\circ} \mathrm{C}$.

\subsection{Preparation of activated coconut husk.}

Activated carbon from coconut husk was prepared according to Sodeinde [19] with some modification. The coconut shell was cleaned from other materials such as coconut fiber or soil. It was soaked in a chemical solution of zinc chloride for 8 hours to become activated carbon. The activated carbon was further treated with $\mathrm{HCl}$. The soaked coconut husk is then sun-dried and ground with a manual grinding machine. Activated coconut husk, then put in a furnace and burned at $650{ }^{\circ} \mathrm{C}$ at the different contact time, which are 1, 2, 3, 4, and 5 hours. The carbonized coconut shell was then crushed to become charcoal.

\subsection{Preparation of dye solution.}

$30 \mathrm{mg}$ remazol red dyes were added to $1000 \mathrm{ml}$ deionized water to prepare $30 \mathrm{mg} / \mathrm{L}$ of dye solution. Preparation of dye solution was carried out using a volumetric flask, and the dye solution prepared was used for the dye adsorption experiment. 


\subsection{Determination of wavelength of remazol red dye.}

In order to carry out batch adsorption experiments, the wavelength of Remazol Red dye must be determined first. For this purpose, the dye solution was prepared for a range of 10 $\mathrm{mg} / \mathrm{L}$ to $50 \mathrm{mg} / \mathrm{L}$. UV-Vis spectrophotometer was used to test the solutions. The wavelength of remazol red dye was determined through the detection of the same wavelength in the solutions.

\subsection{Standard curve of dyes solution.}

The standard curve plays an essential role in determining the concentration of dyes after the experiment. The standard curve needs to be constructed to evaluate the effectiveness of any dye removal techniques, especially by using the calorimetric method. At ambient conditions (a $\mathrm{pH} 7$ and temperature of $25^{\circ} \mathrm{C}$ ), for example, evaluating dye removal concentration is at its best condition. During the preparation of the standard curve, $10 \mathrm{mg} / \mathrm{L}$ until $50 \mathrm{mg} / \mathrm{L}$ of dyes were prepared, and the reading gained through the UV-Vis spectrophotometer was recorded.

\subsection{Batch adsorption for remazol red dye removal.}

Batch adsorption experiment is important in optimizing the process condition for dye adsorption onto adsorbents. The effect of absorbent types and initial dye concentration was studied by setting up a batch experiment.

\subsection{Effects of types of adsorbent used.}

Adsorption studies were performed by preparing $0.2 \mathrm{~g}$ adsorbent media and $100 \mathrm{~mL}$ dye solution into $250 \mathrm{ml}$ conical flasks. The adsorbent was varied into raw coconut husk and 5 types of modified activated coconut husk. These flasks were then placed on an orbital shaker at $180 \mathrm{rpm}$ at $29^{\circ} \mathrm{C}$. The contact time was manipulated from $30,60,90,120,150$, and 180 minutes. Each of the supernatants was separated from the sorbent by centrifugation for 4 minutes at $4000 \mathrm{rpm}$ with the temperature set at $29{ }^{\circ} \mathrm{C}$ before the dye solutions were tested by using UV-Vis spectrophotometer at $664.5 \mathrm{~nm}$ wavelength. The experiment was repeated three times to get better results. The dye adsorbed amount be calculated using a mass balance relationship as the equation below:

Percent removal $=\frac{\left(C_{v}-C_{o}\right)}{C_{o}} \times 100 \frac{\left(C_{v}-C_{o}\right)}{C_{o}} \times 100$

Where $\mathrm{Cv}$ is the solution concentration after adsorption $(\mathrm{mg} / \mathrm{L})$, and Co is the initial concentration of the remazol red dye solution $(\mathrm{mg} / \mathrm{L})$.

\subsection{Effects of initial dye concentration.}

It is important to know the initial dye concentration to control the parameters in the adsorption process since the effect of initial dye concentration indicates the adsorbent ability to absorb the dye. Dye solutions with concentrations of $10,20,30,40$, and $50 \mathrm{mg} / \mathrm{L}$ were prepared and poured into a centrifuge tube. Each of the centrifuge tubes was filled with $25 \mathrm{ml}$ of dye solution. After that, a fixed amount of adsorbent, which is $0.2 \mathrm{~g} / \mathrm{L}$, was added into the centrifuge tube. Then, the adsorption experiment was carried out according to the method explained earlier. 


\subsection{Characterization of raw coconut husk and activated coconut husk.}

The morphological analysis of the adsorbent was carried out using a scanning electron microscope (SEM). Prior to performing the experiment, the samples were covered by a thin layer of gold. The chemical compositions contain in the adsorbent material were studied using Fourier transform infrared (FTIR). The powder samples were mixed well with potassium bromide $(\mathrm{KBr})$ in the ratio of 1:7 before they were filled into pallet press dies.

\section{Results and Discussion}

\subsection{Effects of types of coconut husk adsorbent on the removal of remazol red dyes.}

Figure 1 shows the removal efficiency of different types of adsorbent on remazol red dye. The adsorbents involved were raw coconut husk and activated coconut husk at different contact times in the furnace, which is 1, 2, 3, 4, and 5 hours. Figure 1 clearly shows that raw coconut husk alone is good but cannot be better than activated coconut husk since the highest dye removal was only $54.7 \%$ in contact time at 180 minutes. The study found that the removal efficiency of adsorbent of raw coconut husk has exceeded 50\%. This is due to the remarkable properties of coir dust, which has good structural stability, high water absorption, and highly porous properties, which enhances the adsorption capacity [9-10]. The graph also displays that the removal efficiency of adsorbent increase with the increasing burning time of activated coconut husk in the furnace. This can be explained by the fact that the adsorbent has become dustier and indirectly, these fine particles increase the surface area of adsorbent and provide additional active sites for the adsorption process [19, 22].

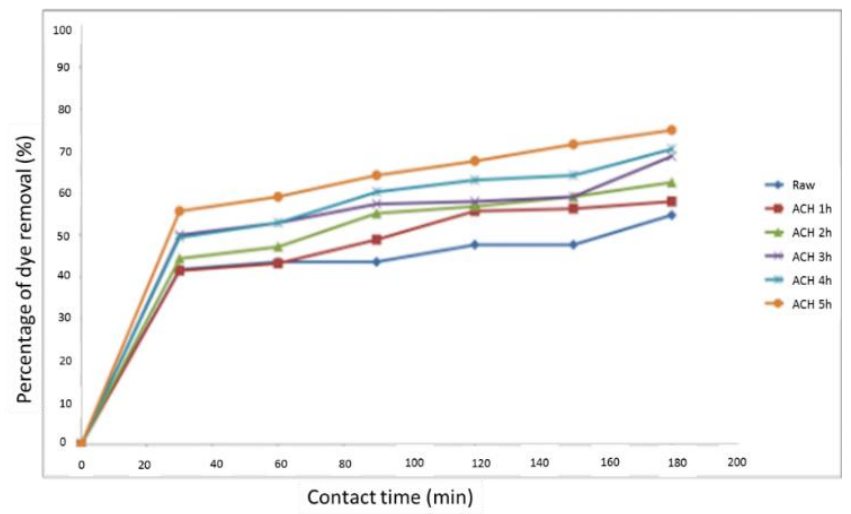

Figure 1. The removal efficiency of remazol red dyes using different types of adsorbents.

The result from Figure 1 was also determined that $\mathrm{ACH} 5 \mathrm{~h}$ was promoted the highest removal efficiency of dyes within 180 minutes of batch adsorption study and achieved maximum removal of around $75 \%$. Thus, $\mathrm{ACH} 5 \mathrm{~h}$ was selected for the next experiment of performance evaluation.

\subsection{Effects of initial dye concentration on the removal of remazol red dyes.}

The dye removal amount is strongly dependent upon the original dye concentration and the binding areas available on an absorbent surface [23]. Figure 2 displays the removal efficiency of ACH 5 hours, in which the initial dye concentration used was between $10 \mathrm{mg} / \mathrm{L}$ to $50 \mathrm{mg} / \mathrm{L}$. Generally, dye removal decreased with a rising value of initial dye concentration. This can be described as adsorption sites are saturated on the adsorbent surface [17-19], [21]. 
Figure 2 indicates the influence of the initial concentration of remazol red dye on the percentage of dye removal throughout contact time. It was observed that for the $10 \mathrm{mg} / \mathrm{L}$ initial dye concentration, the removal of dyes was more than $80 \%$ at the beginning of the adsorption and continued to rise gradually until 180 minutes. The adsorption percentage also decreased with an increase in the initial concentration and increased with a prolonged duration of contact. It is shown in Figure 2 when $50 \mathrm{mg} / \mathrm{L}$ of initial dye concentration is used, the percentage of dye removal only up to $72 \%$ for the longest time, which is 180 minutes. Technically, increasing the initial dye concentration would potentially lead to an increase in the absorbent loading efficiency, which can be attributed due to the high driving force for mass at high initial dye concentration [7, 12-13].

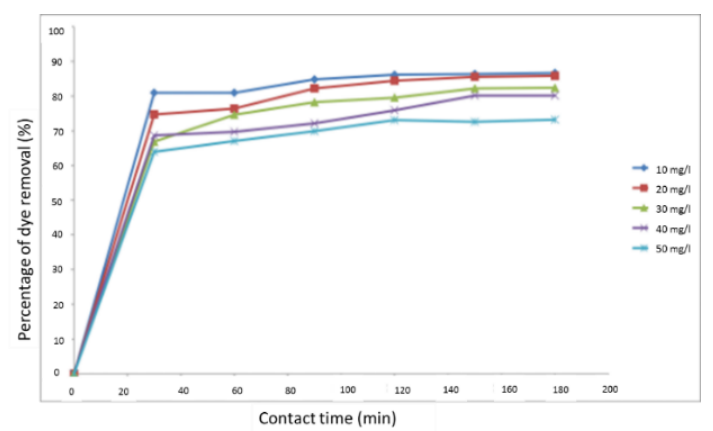

Figure 2. The removal efficiency of remazol red dyes using a different initial dye concentration.

\subsection{Scanning electron microscope (SEM).}

The morphology of adsorbents was monitored using SEM. Figure 3 displays the SEM micrographs of the feature surface of the raw coconut husk $(\mathrm{RCH})$ and activated coconut husk at 5 hours contact time in the furnace ( $\mathrm{ACH} 5 \mathrm{~h})$.

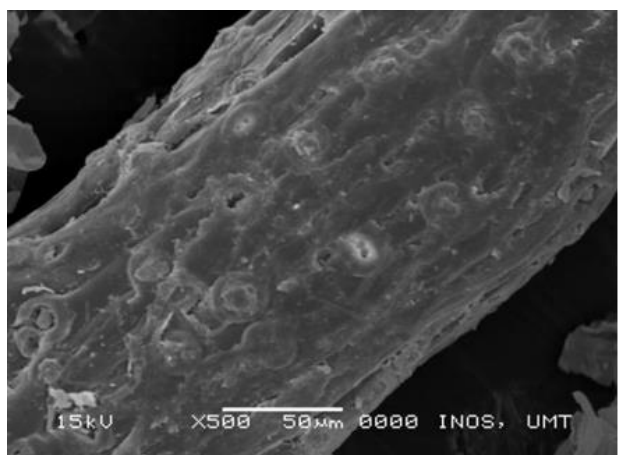

(a)

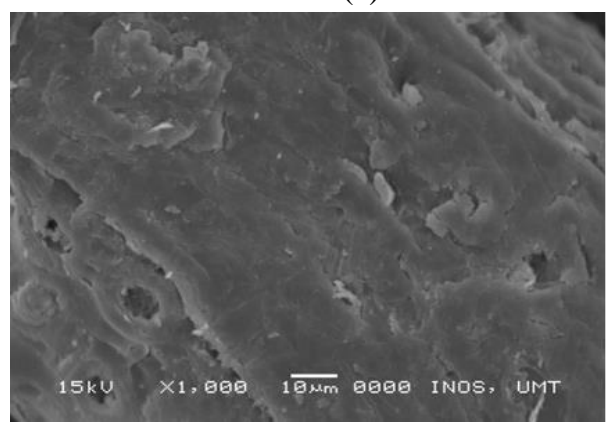

(c)

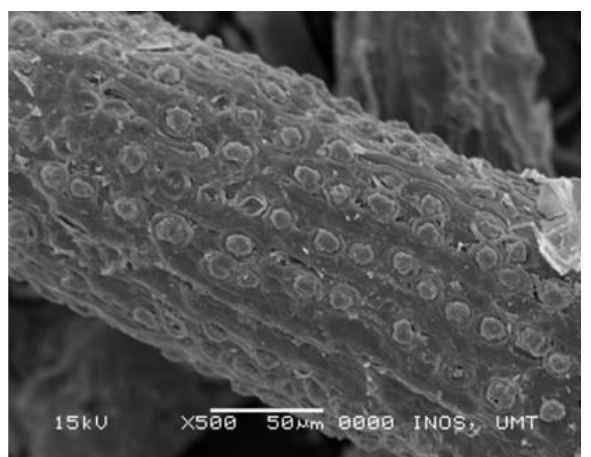

(b)

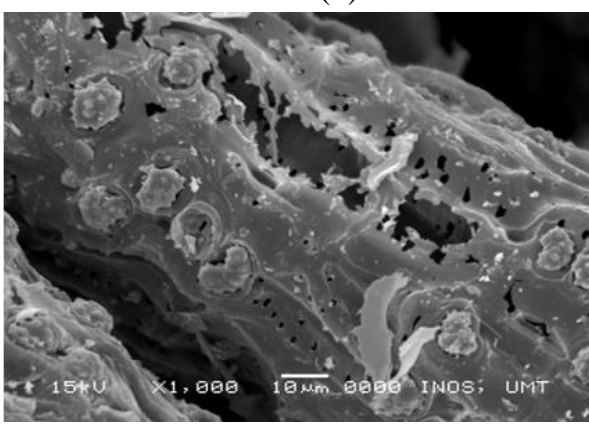

(d)

Figure 3. Surface morphology of adsorbents for (a) RCH at X500, (b) ACH 5h at X500, (c) RCH at X1000, (d) $\mathrm{ACH} 5 \mathrm{~h}$ at $\mathrm{X} 1000$. 
Figure 3 shows the SEM micrograph of the surface morphology of raw coconut husk (Figure $3(\mathrm{a}, \mathrm{c})$ ) and activated coconut husk (Figure $3(\mathrm{~b}, \mathrm{~d})$ ). It can be observed image that many non-uniform aggregations are found in the activated coconut husk (Figure 3 b) comparatively to raw coconut husk image in Figure 3 (a). Moreover, Figure 3 (d) also shows that an activated coconut husk has a rougher surface than raw coconut husk in Figure 3 (d). The rougher surface of the activated coconut husk indicated that the surface area of adsorbent was increased, leading to serving more additional active sites for the adsorption process [2225]. The SEM image also showed that the difference of pores between Figure 3 (c) and Figure 3 (d). This can be seen in the SEM image; many of the pores formed in Figure 3 (d) proved that the activated coconut husk is a good adsorbent compared to untreated raw coconut husk.

\subsection{Fourier transform infrared (FTIR).}

Figure 4 shows the FTIR spectrum of raw coconut husk and activated coconut husk at 5 hours of contact time in the furnace at the wavelength range between 4000 to $400 \mathrm{~cm}^{-1}$. The stretching vibration at $3374.91 \mathrm{~cm}^{-1}$ at raw coconut husk and $3392.78 \mathrm{~cm}^{-1}$ at 5 hours $\mathrm{ACH}$ were attributed to the presence of the O-H group. From the FTIR spectra of raw coconut husk in Figure 4 (a), it can be observed that when the peaks at 1735, 1614, 1545, 1447, 1372, 1262, and $1159 \mathrm{~cm}^{-1}$ are normalized to the cellulose peak at $897 \mathrm{~cm}^{-1}$, most of the peaks have declined and some of it was removed as shown in Figure 4 (b). This indicates that some of the cellulose and lignin components have been removed during the alkaline and bleaching process [30].

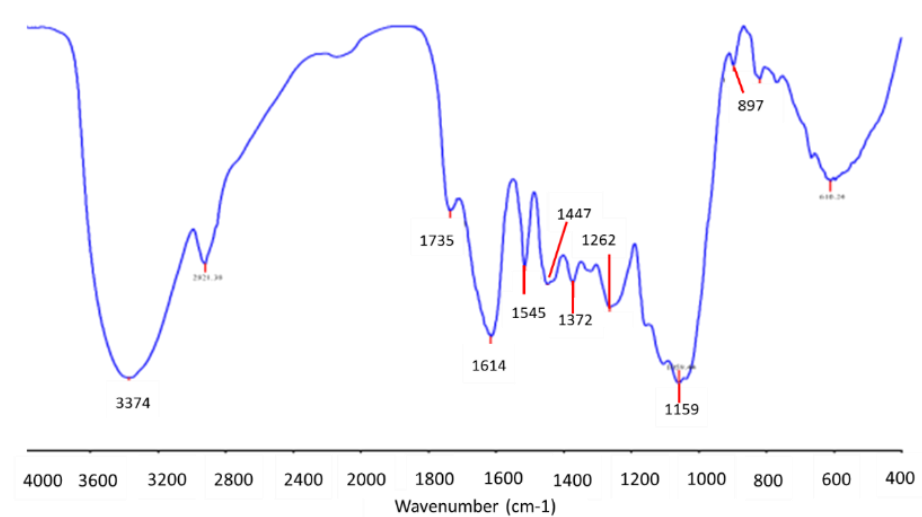

(a)

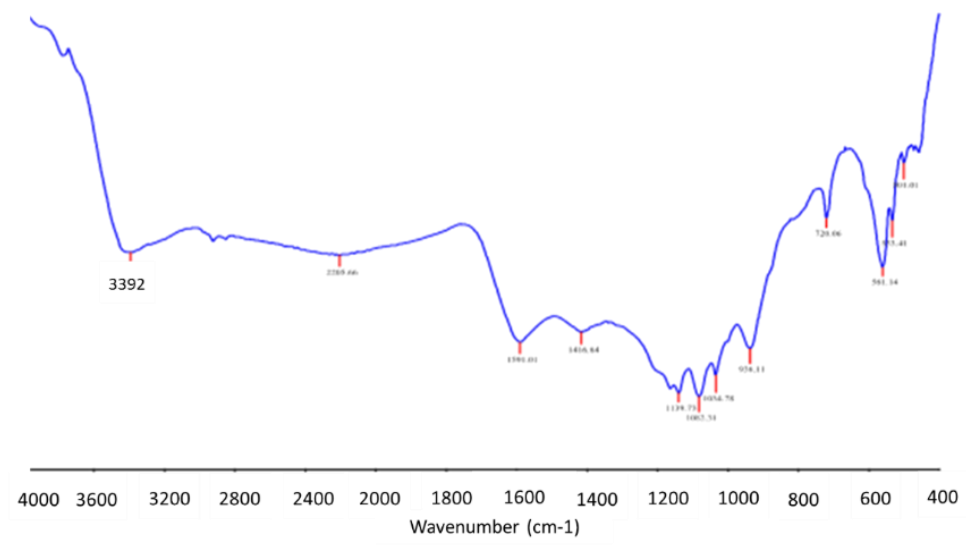

(b)

Figure 4. ATR-FTIR spectrum (a) raw coconut husk and (b) activated coconut husk at 5 hours of contact time in the furnace. 


\subsection{Adsorption isotherm.}

Figure 5 (a) shows that the adsorption capacity increases when the initial dye concentration decrease. The trend is the results from the progressive increase in the electrostatic interaction between the remazol red dyes ion and the active adsorbent site.

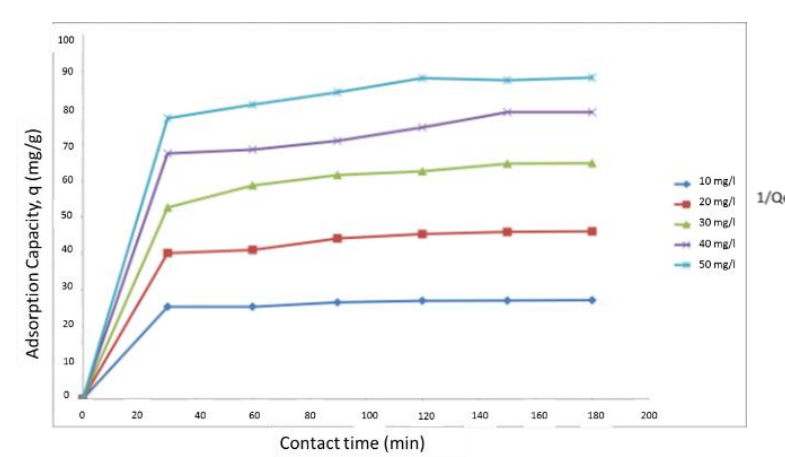

(a)

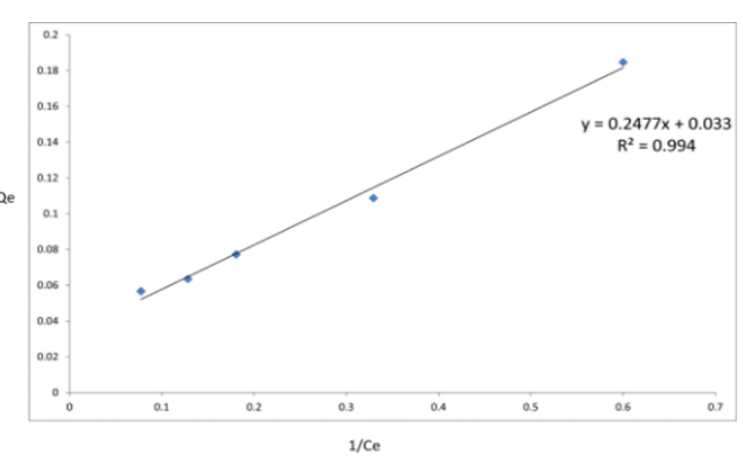

(b)

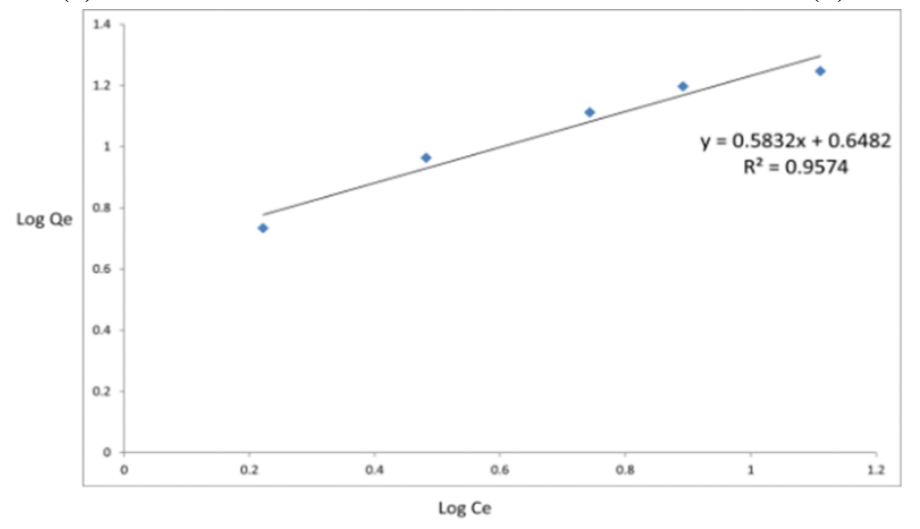

(c)

Figure 5. (a) The adsorption capacity of different initial dyes; (b) Langmuir isotherm graph; Freundlich isotherm graph.

After the adsorption capacity of remazol red dye, removal was determined, the result was manipulated into two types of adsorption isotherm models, which are Langmuir and Freundlich adsorption isotherm. The Langmuir isotherm was evaluated using a model (Equation 2):

$$
\frac{q}{q_{e}}=\frac{b C_{e}}{1+b C_{e}}, \text { where } b=\frac{k a}{k b}
$$

Where $\mathrm{C}_{\mathrm{e}}$ is the concentration of equilibrium $(\mathrm{mg} / \mathrm{L}), \mathrm{q}_{\mathrm{e}}$ is the sorption capacities at equilibrium $(\mathrm{mg} / \mathrm{g})$, while $\mathrm{ka}(\mathrm{mg} / \mathrm{g})$ and $\mathrm{kb}(\mathrm{L} / \mathrm{mg})$ both are constants of Langmuir that related to adsorption capacity and adsorption energy, respectively. The linear plots of $1 / \mathrm{Q}_{\mathrm{e}}$ against $1 / \mathrm{C}_{\mathrm{e}}$ shown in Figure 5 (b), reveal that all adsorbents obey the Langmuir isotherm model.

Freundlich isotherm was determined using Equation 3

$$
\mathrm{q}_{\mathrm{e}}=\mathrm{K}_{\mathrm{f}} \mathrm{Ce}^{1 / \mathrm{n}}
$$

Where, $\mathrm{C}_{\mathrm{e}}$ is the equilibrium concentration of the adsorbate $(\mathrm{mg} / \mathrm{l}), \mathrm{q}_{\mathrm{e}}$ is the amount of adsorbate adsorbed per unit mass of adsorbent $(\mathrm{mg} / \mathrm{g})$, and both $\mathrm{K}_{\mathrm{f}}$ and $\mathrm{n}$ are Freundlich constants with $\mathrm{n}$ giving an indication of how favorable the adsorption process, $\mathrm{K}$ is the adsorption capacity of the adsorbent. 
From Figure 5 (b) above, a plot of $\log \mathrm{q}_{\mathrm{e}}$ versus $\log \mathrm{C}_{\mathrm{e}}$ is a straight line with the $\mathrm{y}$-axis interception that represents the value of $\log \mathrm{K}$ with slope $1 / \mathrm{n}$. The linear plot revealed the Freundlich isotherm's applicability to both adsorbents. From the study of the two sorption isotherms, the value of $\mathrm{R}$ for Langmuir and Freundlich adsorption isotherm was revealed. On the other hand, for the values of maximum adsorption capacities (q), the rate of adsorption (K) and adsorption nature $(\mathrm{R})$ for Langmuir adsorption isotherm was determined. The value of adsorption capacity $(\mathrm{K})$ and intensity of adsorption (n) were determined for Freundlich adsorption isotherm. The comparisons between the two types of adsorption isotherm model were revealed in Table 1.

Table 1. The comparison of Langmuir and Freundlich adsorption isotherm. Langmuir

\begin{tabular}{|c|c|c|c|}
\hline $\mathrm{q}_{\mathrm{m}}(\mathrm{mg} / \mathrm{g})$ & $\mathrm{K}_{\mathrm{L}}(\mathrm{L} / \mathrm{mg})$ & $\mathrm{R}_{\mathrm{L}}$ & $\mathrm{R}^{2}$ \\
\hline 30.303 & 0.133 & 0.118 & 0.994 \\
\hline \multicolumn{4}{|c|}{ Freundlich } \\
\hline $1 / \mathrm{n}$ & $\mathrm{n}$ & $\mathrm{K}_{\mathrm{f}}(\mathrm{mg} / \mathrm{g})$ & $\mathrm{R}^{2}$ \\
\hline 0.5832 & 1.7146 & 4.4484 & 0.9574 \\
\hline
\end{tabular}

From the study of the two sorption isotherms, it was observed that Langmuir isotherm has a better fitting model than Freundlich isotherm and also has a higher correlation coefficient, $\mathrm{R}$, for both adsorbent graphs. This was further confirmed from the values of adsorption capacity for ACH 5h, which was observed to be higher than $\mathrm{RCH}$. This shows that this adsorbent has a monolayer surface. Monolayer surface means that the entire part of the adsorption sites are equivalent, and each site can only accommodate one molecule.

\section{Conclusion}

The findings of this study reveal the potential of activated coconut husk as an excellent low-cost adsorbent to replace activated carbon for the removal of remazol red dye in wastewater treatments. The findings reveal that the percentage removal of remazol red dye by the treated bio adsorbent was higher compared to the untreated bio adsorbent. Besides, studies have shown that the longer burning time in the furnace for carbonization also increases the surface area of the bio adsorbent, making them more porous and thus increasing the adsorption between the bio adsorbent and the remazol red dyes. As for the initial dye concentration test, it shows that the higher the dye concentration, the lower the percentage of red remazol dyes removal, but the adsorption capacity will increase. The Scanning Electron Microscope (SEM) shows that the morphology of the treated bio adsorbent is rough and has many pores compare to the raw adsorbent. The FTIR analysis proved the reduction of peaks indicates the removal of lignin and hemicellulose by alkaline and bleaching pretreatment. Therefore, it can be concluded that the objectives in this study have been successfully achieved, and the outcome of this study can be a good reference for further development in the related research.

\section{Funding}

This research received no funding.

\section{Acknowledgments}

The authors wish to acknowledge the Faculty of Ocean Engineering, Technology, and Informatics, Universiti Malaysia Terengganu, for research facilities and supports. 


\section{Conflicts of Interest}

\section{The authors declare no conflict of interest.}

\section{References}

1. Adegoke, K.A.; Solomon, O. Dye sequestration using agricultural wastes as adsorbents. Water Resour. Ind. 2015, 12, 8-24. https://doi.org/10.1016/j.wri.2015.09.002.

2. Lellis, B.; Fávaro-Polonio, C.Z.; Pamphile, J.A.; Polonio, J.C. Effects of textile dyes on health and the environment and bioremediation potential of living organisms. Biotechnol. Res. Innov. 2019, 3, 275-290, https://doi.org/10.1016/j.biori.2019.09.001.

3. Jawad, A.H.; Razuan, R.; Appaturi, J.N.; Wilson, L.D. Adsorption and mechanism study for methylene blue dye removal with carbonized watermelon (Citrullus lanatus) rind prepared via one-step liquid phase $\mathrm{H}_{2} \mathrm{SO}_{4}$ activation. Surfaces and Interfaces 2019, 16, 76-84, https://doi.org/10.1016/j.surfin.2019.04.012

4. Katheresan, V.; Kansedo, J.; Lau, S.Y. Efficiency of various recent wastewater dye removal methods: A review. J. Environ. Chem. Eng. 2018, 6, 4676-4697, https://doi.org/10.1016/j.jece.2018.06.060

5. Nasar, A.; Mashkoor, F. Application of polyaniline-based adsorbents for dye removal from water and wastewater - a review. Environ. Sci. Pollut. Res. 2019, 26, 5333-5356, https://doi.org/10.1007/s11356-0183990-y.

6. Kit, N.H.; Hadibarata, T.; Yuniarto, A.; Sari, A.A. Removal of triphenylmethane dye from aqueous solutions through an adsorption process over waste materials. Biointerface Res. Appl. Chem. 2020, 10, 5572-5579, https://doi.org/10.33263/BRIAC104.772779.

7. Kecić, V.; Kerkez, Đ, Prica, M.; Lužanin, O.; Bečelić-Tomin, M.; Pilipović, D.T.; Dalmacija, B. Optimization of azo printing dye removal with oak leaves-nZVI/ $\mathrm{H}_{2} \mathrm{O}_{2}$ system using statistically designed experiment. J. Clean. Prod. 2018, 202, 65-80. https://doi.org/10.1016/j.jclepro.2018.08.117.

8. Kocaman, S. Removal of methylene blue dye from aqueous solutions by adsorption on levulinic acidmodified natural shells. Int. J. Phytoremediation 2020, 22, 885-895, https://doi.org/10.1080/15226514.2020.1736512.

9. Crini, G.; Torri, G.; Lichtfouse, E.; Kyzas, G.Z.; Wilson, L.D.; Morin-Crini, N. Dye removal by biosorption using cross-linked chitosan-based hydrogels. Environ. Chem. Lett. 2019, 17, 1645-1666, https://doi.org/10.1007/s10311-019-00903-y.

10. Li, Y.; Xiao, H.; Pan, Y.; Wang, L. Novel Composite Adsorbent Consisting of Dissolved Cellulose Fiber/Microfibrillated Cellulose for Dye Removal from Aqueous Solution. ACS Sustain. Chem. Eng. 2018, 6, 6994-7002, https://doi.org/10.1021/acssuschemeng.8b00829.

11. Lagashetty, A.; Ganiger, S. K.; Reddy, S. Microwave Derived Nano Sized Zirconium Vanadate as an Adsorbent for Heavy Metal Ions. Lett. Appl. NanoBioScience 2020, 9, 1420-1426, https://doi.org/10.33263/LIANBS93.14201426.

12. Ouslimani, N.; Boureghda, M.Z.M. Removal of Directs Dyes from Wastewater by Cotton Fiber Waste. Int. J. Waste Resour. 2018, 08, https://doi.org/10.4172/2252-5211.1000330.

13. Bulgariu, L.; Escudero, L.B.; Bello, O.S.; Iqbal, M.; Nisar, J.; Adegoke, K.A.; Alakhras, F.; Kornaros, M.; Anastopoulos, I. The utilization of leaf-based adsorbents for dyes removal: A review. J. Mol. Liq. 2019, 276, 728-747, https://doi.org/10.1016/j.molliq.2018.12.001.

14. Zhou, Y.; Lu, J.; Zhou, Y.; Liu, Y. Recent advances for dyes removal using novel adsorbents: A review. Environ. Pollut. 2019, 252, 352-365, https://doi.org/10.1016/j.envpol.2019.05.072.

15. Domingues, J.T.; Orlando, R.M.; Sinisterra, R.D.; Pinzón-García, A.D.; Rodrigues, G.D. Polymer-bixin nanofibers: A promising environmentally friendly material for the removal of dyes from water. Sep. Purif. Technol. 2020, 248, https://doi.org/10.1016/j.seppur.2020.117118

16. Kaykhaii, M.; Sasani, M.; Marghzari, S. Removal of Dyes from the Environment by Adsorption Process. Chem. Mater. Eng. 2018, 6, 31-35, http://doi.org/10.13189/cme.2018.060201.

17. Munagapati, V.S.; Yarramuthi, V.; Kim, Y.; Lee, K.M.; Kim, D.S. Removal of anionic dyes (Reactive Black 5 and Congo Red) from aqueous solutions using Banana Peel Powder as an adsorbent. Ecotoxicol. Environ. Saf. 2018, 148, 601-607, https://doi.org/10.1016/j.ecoenv.2017.10.075.

18. Abdul Karim, S.K.; Lim, S.F.; Chua, S.N.D.; Salleh, S.F.; Law, P.L. Banana Fibers as Sorbent for Removal of Acid Green Dye from Water. J. Chem. 2016, 2016, http://dx.doi.org/10.1155/2016/9648312.

19. Sodeinde, O.A. Preparation of a Locally Produced Activated Carbon from Coconut Shells and Its Use in Reducing Hexamine Cobalt(III). Int. J. Chem. Eng. Appl. 2012, 3, 67-71, https://doi.org/10.7763/IJCEA.2012.V3.162.

20. Chong, M.Y.; Tam, Y.J. Bioremediation of dyes using coconut parts via adsorption: a review. SN Appl. Sci. 2020, 2, https://doi.org/10.1007/s42452-020-1978-y

21. Okafor, P.C.; Okon, P.U.; Daniel, E.F.; Ebenso, E.E. Adsorption capacity of coconut (cocos nucifera L.) shell for lead, copper, cadmium and arsenic from aqueous solutions. Int. J. Electrochem. Sci. 2012, 7, 1235412369. 
22. Pathania, D.; Sharma, S.; Singh, P. Removal of methylene blue by adsorption onto activated carbon developed from Ficus carica bast. Arab. J. Chem. 2013, 10, S1445-S1451, http://dx.doi.org/10.1016/j.arabjc.2013.04.021.

23. Pavani, K.V.; Srujana, N.; Preethi, G.; Swati, T. Immobilization of lignin peroxidase from Alcaligenes aquatilis and its application in dye decolorization. Lett. Appl. NanoBioScience 2020, 2, 1058-1063, https://doi.org/10.33263/LIANBS92.10581063.

24. Xia, L.; Li, C.; Zhou, S.; Fu, Z.; Wang, Y.; Lyu, P. Utilization of waste leather powders for highly effective removal of dyes from water. Polymers (Basel). 2019, 11, 1-15, http://doi.org/10.3390/polym11111786.

25. Ma, J.; Shen, Y.; Shen, C.; Wen, Y.; Liu, W. Al-doping chitosan-Fe(III) hydrogel for the removal of fluoride from aqueous solutions. Chem. Eng. J. 2014, 248, 98-106, http://dx.doi.org/10.1016/j.cej.2014.02.098

26. Banerjee, S.; Chattopadhyaya, M.C. Adsorption characteristics for the removal of a toxic dye, tartrazine from aqueous solutions by a low cost agricultural by-product. Arabian. J. Chem. 2017, 10, S1629-S1638, http://dx.doi.org/10.1016/j.arabjc.2013.06.005.

27. Zhang, H.; Tang, L.; Wang, J.; Yu, J.; Feng, H.; Lu, Y.; Chen, Y.; Liu, Y.; Wang, J.; Xie, Q. Enhanced surface activation process of persulfate by modified bagasse biochar for degradation of phenol in water and soil: Active sites and electron transfer mechanism. Colloids Surfaces A Physicochem. Eng. Asp. 2020, 599, https://doi.org/10.1016/j.colsurfa.2020.124904.

28. Xia, L.; Zhang, C.; Wang, A.; Wang, Y.; Xu, W. Morphologies and properties of Juncus effusus fiber after alkali treatment. Cellulose 2020, 27, 1909-1920, https://doi.org/10.1007/s10570-019-02933-9.

29. Li, J.; Li, H., Yuan, Z.; Fang, J.; Chang, L.; Zhang, H.; Li, C. Role of sulfonation in lignin-based material for adsorption removal of cationic dyes. Int. J. Biol. Macromol. 2019, 135, 1171-1181, https://doi.org/10.1016/j.ijbiomac.2019.06.024.

30. Rosa M.F.; Medeiros, E.S.; Malmonge, J.A.; Gregorski, K.S.; Wood, D.F.; Mattoso, L.H.C.; Glenn, G.; Orts, W.J.; Imam, S.H. Cellulose nanowhiskers from coconut husk fibers: Effect of preparation conditions on their thermal and morphological behavior. Carbohydr. Polym. 2010, 81, 83-92, https://doi.org/10.1016/j.carbpol.2010.01.059. 